The Lisbon treaty and the commission's appointment

Wim Van Gestel

DEPARTMENT OF MANAGERIAL ECONOMICS, STRATEGY AND INNOVATION (MSI) 


\title{
The Lisbon Treaty and the Commission's Appointment
}

\author{
Wim Van Gestel \\ Katholieke Universiteit Leuven
}

November 13, 2012

\begin{abstract}
This paper looks at EU trade policy and more specifically at the negotiating mandate the Council must grant the Commission to start trade negotiations. The negotiating mandate is a set of directives that impose limits to the proposals the Commission can make. As such the mandate is legally binding and defendable in a court of justice. However, authors such as Kerremans (2004b) and Damro (2007) also point out a different way of looking at the mandate by arguing that it sets out the maximum concessions the Council is willing to make during trade talks and that the mandate can thus be considered a signaling device. In this paper I analyze this proposed second role of the negotiating mandate in EU trade policy making by decoupling the two perspectives on the negotiating mandate. The results of the model show that when individual Council members can communicate with the Commission, there exists a signaling equilibrium in which the Commission complies with the mandate.
\end{abstract}




\section{Introduction}

In this paper I analyze the appointment of the Commission and how changes induced by the Lisbon Treaty affect the type of Commission that ultimately is appointed. The paper is in that respect closely related to the work of Crombez and Hix (2011), but whereas they assume perfect information, this paper focuses on asymmetric information. I make the claim that even though the Treaty of Lisbon left the Commission's appointment procedure unaltered, future Commissions are more likely to represent the European Parliament's (EP) interests because of the increased use of codecision procedure where the EP has veto rights and amendment rights. To develop this argument, the paper presents a two stage game theoretical model with asymmetric information where first the Commission is appointed, after which the policy making process takes place.

Political scientists and economists have long been aware that rules and procedures shape decisions and their outcomes. Condorcet (1785) shows that using simple majority rule in legislation can lead to undesirable effects such as preference cycling. Arrow (1951) proves that there exists no single procedure that can translate individual preferences into a coherent group decision without having some concentration of power, with a political actor's power defined as his ability to affect the outcome of the political process and to end up with a policy closer to its preferred outcome. Yet these preferences actors hold in the legislative arena are not exogenous. Agenda setting committees, for instance, are appointed by legislators and are therefore not independent from their parent bodies.

An interesting contribution to the notion of appointing an agent under asymmetric information is made by Johns (2007). In her paper Johns discusses the scenario where two principals with diverging preferences collectively appoint an agent for informational purposes. The agent provides information with regards to the consequences of policy, after which both principals negotiate a policy outcome. Johns finds that when each policy maker is bound to adhere to the bargaining outcome, "moderate" bureaucrats are most preferred. In contrast, when at least one policy maker can leave the bargaining table and exercise an outside option, a bureaucrat with preferences similar to that policy maker's direction can be optimal.

Johns' model was designed to evaluate the UN weapons inspections in Iraq, but there are also other situations where committees are chosen by multiple legislative bodies. In the European Union (EU) the Commission is appointed by both the European Parliament (EP) and the Council. The appointed Commission therefore reflects the preferences of both the Council and the EP, at least to the degree that both have a say during the appointment procedure. A key difference with the model presented by Johns (2007) is that the Commission's role is not limited to that of an information transmitter: after its appointment, the Commission is actively involved in the policy making process as an agenda 
setter, a committee that has the authority to make proposals. Changes in the policy making procedures may therefore have an impact on the appointment process: the Commission plays both an informational and a distributional role whereas the agent in Johns' model only has an information role.

Even though the codecision procedure was already used extensively before the Lisbon Treaty, there were some key policy areas in which the EP had a merely consultative role in the legislative process. On trade issues, for example, the only institutions that were formally involved in the legislative process were the European Commission and the Council. The Lisbon Treaty further expands the scope of the codecision procedure. In practice this means that now the EP has veto right and amendment right in a wide range of other policy issues.

In the endogenous Commission models, it is sufficient to look only at the influence of the EP's veto right without explicitly considering the amendment right in other policy areas. To see this, suppose that the EP can amend a proposal. Since I assume below that players derive their utility from locational preferences in one policy dimension, the amended proposal is then closer to the EP's ideal policy and further away from the Commission's ideal than the original proposal. Both in the asymmetric and perfect information models used in this paper, the Commission that the Council and the EP prefer to appoint is located between their ideal preferences. The Council thus prefers the Commission's original proposal to the EP's amended proposal. When the Council does not accept the EP's amendments, the codecision procedure prescribes that the Conciliation Committee convenes. This committee brings together Council members and MEPs to find an agreement on a new joint text. If no agreement can be found, the act is deemed not to have been adopted. Since both want to move away from the Commission's proposal in different directions, amendments to the Commission's original proposal in either direction are blocked by the other party. In practice, the only decision that can then be made in the Conciliation Committee is whether to accept the Commission's original proposal or not. In models with an endogenous agenda setter, the EP cannot amend the Commission's original proposal and therefore behaves as if it operates under a closed rule procedure where it only has veto right.

The goal of this paper is to look whether changes in the policy making rules have a clear impact on the Commissioners that are appointed. I find that the policy making process under asymmetric information strongly affects what Commissioners are appointed. Before the Lisbon Treaty, the both the EP and the Council prefer to appoint a Commission that is relatively close to the Council's preferences. Since the EP has little formal say during the policy making process, it wants the Council to be able to make a more informed decision and to defeat the status quo for a wide range of status quos. Even though the setup of this paper's model is completely different from Johns' (2007) model, its findings are closely related: the principal with the outside option of defaulting 
to the status quo should be more informed than the principals without that option.

After the introduction of the Lisbon Treaty, the EP itself requires better information with regards to the consequences of policy, because otherwise the uncertainty would lead the EP to prefer the status quo over the Commission's proposals. This is undesirable for both the EP and the Council, and therefore both prefer a Commission closer to the EP than before the Lisbon Treaty. I also show that these results are robust enough to allow for various types of negotiations during the appointment stage, such as take-it-or-leave-it offers made by the Council and alternate offerings by both the Council and the EP with different probabilities of being selected to make a proposal.

The remainder of the paper is structured as follows. Section 2 discusses the literature on EU procedures in general with a special focus on Commission appointment and asymmetric information. Section 3 uses a perfect information model that confirms the results put forward by other authors that use similar approaches. Section 4 investigates the scenario with asymmetric information regarding the consequences of policy. It studies the policy making process, first before and then after the introduction of the Lisbon Treaty. I then use the equilibria I found to show how the Commission appointed in equilibrium changes because of alterations to the policy making process. Finally, section 5 formulates the paper's main conclusions.

\section{Literature}

In the EU decision making often requires overcoming disagreement and controversy and is therefore a widely studied research area. With 27 member states - each represented by its national government ministers in the Council - and constant reforms of its legislative process, this is not very surprising. Tsebelis (2002) acknowledges the EU's complexity and describes it as "a blatant exception to all traditional classifications of international institutions". He takes a veto players approach to assess policy, and finds that adding a veto player increases the stability of policy. However, this approach does little to explain the location of policy. Steunenberg (1994) and Crombez $(1996 ; 1997)$ use game theory and a spatial framework to identify which actors have procedural power under different legislative procedures.

Most formal models that study the EU institutionalism assume an exogenous Commission, that is, the preferences of the Commission are fixed throughout the game (e.g. Crombez, 1996; Pollack, 1998; Tsebelis, 1994). In reality the Commission is appointed by the Council and the EP. Therefore Hug (1997, 2003) argues that preferences of supranational actors are related to those of the actors who select or appoint them. Noteworthy exceptions to the exogenous assumption are the theoretical models put forward by Crombez (1997b) and Crombez 
and Hix (2011). They use a perfect information model to study how changes to the appointment procedure in the different treaties have had an impact on the Commission's preferences relative to the Council and the EP and they assess the potential gridlock that can result from this. When discussing the Lisbon Treaty, the authors argue that it has no impact on the Commission, because the appointment procedure itself remains unaltered by treaty changes. Moreover, Crombez and Hix only study the introduction of the codecision procedure by the Maastricht Treaty and not later extensions of that procedure.

Another exception to the exogenous assumption is put forward by Napel and Widgrén (2008). They explicitly study the Commission's appointment process. The main finding of their paper is that in equilibrium commissioners duplicate the policy preferences of Council representatives. This seems to contradict anecdotal evidence and more rigorous empirical studies such as König et al. (2007) and Rasmusen (2003), who suggest that the Commission and EP exhibit a much less conflictive relationship than the Commission and the Council. However, Napel and Widgrén (2008) argue that it are the internal decision rules that prevent the Commission from being a Council clone. Indeed, the Council operates under supermajority rule, whereas the Commission uses simple majority rule in its decision making. Therefore, in accordance with Black's (1948) median voter theorem, the Commission's position is determined by its median voter whose preferences coincide with a moderate Council member under the duplication hypothesis. And because the EP also uses simple majority rule, its pivotal member tends to be a like-minded political moderate. This suggests that mere similarity between the EP and the Commission does not imply a powerful EP during the appointment stage, but that a careful analysis is required to make such statements.

The models put forward by Crombez and Hix (2011) and Napel and Widgrén (2008) study the Commission's appointment in great detail, but make the assumption that all players have perfect and symmetric information. Yet Gilligan and Krehbiel $(1987,1989)$ have shown that one of the main rationales for delegation to a committee is to provide incentives to specialize and acquire better information with regards to the consequences of policy. Franchino (2005) translates these principles to the EU legislative process and develops a theoretical framework that analyzes delegation to an exogenous Commission for informational purposes. As a result of the specialization, the Commission is better informed about the consequences of policy and this information can be transmitted in proposals to the Council and the EP. This directly impacts the preferences of the latter two institutions with regards to what Commission members are appointed. It is exactly this link between Commission appointment and the legislative process this paper elaborates on. 


\section{A Perfect Information Model}

In this section I first explore what happens if the EP, the Council and the Commission are perfectly informed on the consequences of policy. Because the Commission's proposals do not convey any additional information as of yet, there are only distributional effects to consider when the EP and the Council appoint the Commission.

In the formal analysis, I assume for simplicity that all institutions vote with simple majority rule. Even though in reality the Council employs supermajority rule, this assumption does not alter the interpretation of our findings. It reduces mathematical complexity and facilitates further analysis by focusing on the changing balance of power between the Council and the EP when they appoint the Commission under different legislative procedures. The assumption of simple majority vote reduces the institution to a unitary actor, represented by the median voter (Black, 1948). I let $C, H$ and $A$ denote the Council, the $\mathrm{EP}$ and the Commission respectively.

The policy space $\mathbb{R}$ is assumed to be one dimensional. This dimension could reflect degrees of trade liberalization, for example, with actors on the right being more in favor than actors on the left. I discern two different scenarios and sequences of play. First, corresponding to the scenario before the Lisbon Treaty, the Commission drafts a proposal and if the Council prefers it over the status quo, it becomes policy. Otherwise the status quo prevails. Second, under the rules introduced by the Lisbon Treaty, the Commission also drafts a proposal, but now both the Council and the EP need to prefer it over the status quo for it to become policy. ${ }^{1}$

Under perfect information the Commission acts as an agenda setter that chooses the policy it prefers most out of the winset, that is, the range of policies that defeat the status quo under the policy making procedure. While the winset becomes smaller when the EP has formal veto power, this does not alter the fact that the Council and the EP prefer a Commission that is closer to their ideal. When the Council (EP) succeeds at appointing a Commission that is closer to its ideal, the policy the Commission chooses from among the policies in the winset is closer to the Council's (EP's) ideal. This principle leads to the following proposition.

Proposition 1 Under the assumption of perfect information, the appointed Commission has preferences inbetween the Council's and EP's ideal policy. Legislative institutions prefer an agenda setter closer to their ideal preferences, regardless of the formal power they have. Therefore there is no impact of the Lisbon Treaty on the Commission appointment in the presence of perfect information.

\footnotetext{
${ }^{1}$ In this paper I thus look explicitly at policy areas in which the Lisbon Treaty extended the use of the codecision procedure, or where the EP obtained veto right such as in trade issue.
} 


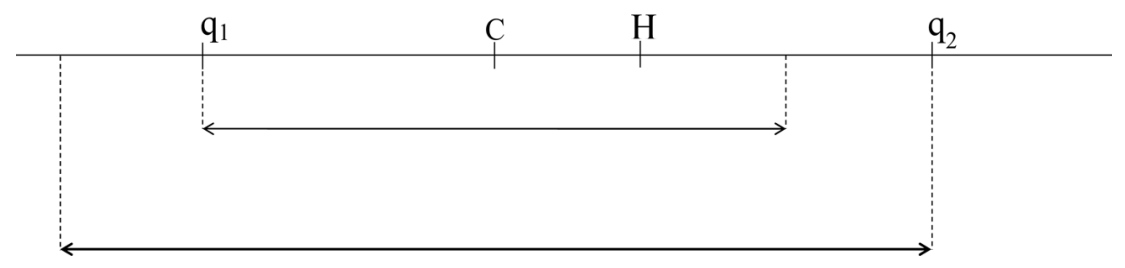

Figure 1: Winsets under pre-Lisbon rules

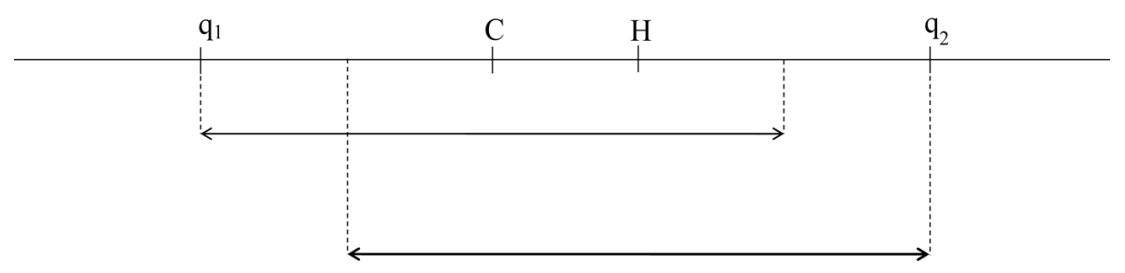

Figure 2: Winset under Lisbon Treaty rules

Figure 1 shows the winsets for two different status quos, $q_{1}$ and $q_{2}$, and when the EP is powerless in the policy making process as it was before the Lisbon Treaty. This situation corresponds to the legislate procedure in trade issues, for example, where the EP had only a consultative role. In the scenario where the status quo is $q_{1}$ the thin arrow indicates the winset containing all the proposals the Commission can make that can defeat the status quo $q_{1}$. The bold arrow indicates the winset when $q_{2}$ is the status quo. Since in each situation the Commission picks a policy from the relevant set that is closest to its own ideal, the Council and the EP want to appoint a Commission that has an ideal policy very close tot theirs. Indeed, if $A$ is close to $H$, he proposes a policy from the winset that is close to $H$ and the reverse is true if $A$ is close to $C$.

Figure 2 indicates what happens for the same status quos and legislators' preferences when the EP has formal veto power as under the Lisbon Treaty. The size of the winset relating to $q_{1}$, represented again by the thin arrow, remains as large as in the previous figure. However, the size of the winset if $q_{2}$ is the status quo changes. This is because now the EP must vote in favor of the proposal and the EP is more conservative relative to $q_{2}$ than the Council. Yet one can again see that the Council and the EP both prefer an agenda setter that is closer to their ideal preferences: if $A$ is close to $H$, he will propose a policy from the winset that is close to $H$ and the reverse is true if $A$ is close to $C$.

Figures 1 and 2 intuitively show why perfect information models such as those presented in Crombez (1997b) and Crombez and Hix (2010) predict that the introduction of the Lisbon Treaty itself has no influence on the preferences 


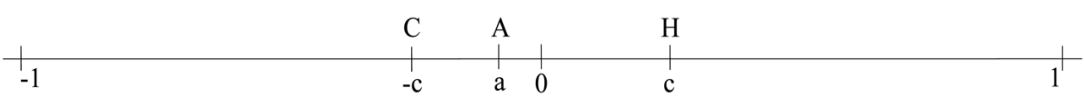

Figure 3: Spatial representation of the preferences

of legislators with respect to Commission appointment. Both legislative bodies prefer a Commission that is closer to itself, because this guarantees that the proposals made are closer to their ideal policy. On the basis of this model, one could therefore expect that in absence of changes to the Commission's appointment procedure, the Lisbon Treaty has no impact on the type of Commission that is appointed. In the next section I relax the assumption of perfect information.

\section{An Asymmetric Information Model}

This section splits up the analysis into two parts: the appointment stage and the policy making process. First I analyze the policy making process both before and then after the Lisbon Treaty. Next I look at how the policy making process shapes the preferences of the legislators with regards to the type of Commission they appoint and show that the Commission is more moderate under Lisbon than before.

\subsection{The Policy Making Process}

This section looks at how the Council, the Commission and the EP set policy through the policy making process under asymmetric information. Just as in the perfect information model, $C, H$ and $A$ denote the Council, the EP and the Commission respectively. The policy space $\mathbb{R}$ is assumed to be one dimensional. For simplicity and without loss of generality I normalize the one-dimensional policy space such that the average ideal policy result of the Council and the EP is equal to zero as illustrated in Figure 3.

The ideal policy result of the EP is set equal to the value $c$. Because of the normalization of the policy space, the ideal policy result of the Council can then be set equal to $-c$. The ideal policy result of the agenda setting Commission is assumed to be equal to $a$ with $a \in \mathbb{R}$. Values of $a$ outside of the legislators are always dominated by values inside this interval and are Pareto inefficient, so $a$ $\in[-c, c]$.

Actors have preferences over the results of policies, not over policies as such. For instance, they do not care whether a tax rate is $5 \%$ or $50 \%$, but they care about what the consequences are these tax rates. There is some uncertainty about how policies translate into outcomes and this is captured by the equation $r(p)=p+\omega$, where $r(p)$ is the result of policy $p$ and $\omega$ represents an external 
shock. $^{2}$ Whereas all players know the distribution of the shock, the actual realization of $\omega$ is known only by the Commission. The Commission has superior information because it specializes in the policy issue at hand. There is a cost to this specialization, but I assume, in the vocabulary of Gilligan and Krehbiel $(1987,1989)$, that the cost of specialization is sufficiently low for the closed rule procedure to provide the Commission the necessary incentives to do so. Actors prefer policy results that are closer to rather than farther away from their ideal result. Actors have Euclidean preferences. In particular actor $x$ with ideal policy $p_{x}$ derives utility $U_{x}(p)=-\left(r(p)-p_{x}\right)^{2}$ from policy $p$.

Our theoretical model is based on the closed rule model put forward by Gilligan and Krehbiel (1987). This is a type of equilibrium where partial separation is possible for a range of $\omega$, meaning that for some values of $\omega$ the Commission can successfully propose a policy that signals that it is improving over the status quo for the legislators. Another type of equilibrium is a pure pooling one, where the agenda setter makes a random proposal and the legislators always vote against it. An equilibrium with pure pooling has lower expected utility for all players and is less interesting to look into when considering endogenous agenda setters. Hence I choose to base our model on the partial separating equilibrium type.

\subsection{Before Lisbon}

Before the introduction of the Lisbon Treaty, the EP has no power in the policy making process. In the vocabulary of Johns (2007), it does not have the outside option of deferring to the status quo. Therefore its wishes can be ignored by the other institutions and the only actors that are actively involved in this stage of the game are the Council and the Commission.

The sequence of the game is as follows. First Nature reveals $\omega$ to the Commission. This means that the Commission specializes in the policy issue at hand and learns about the relationship between policies and outcomes. In the second stage the informed Commission drafts a policy proposal $b$ and offers it to the Council. In the third and final stage the Council votes on the proposal. If it accepts the proposal, the proposal is adopted and otherwise the status quo remains.

The equilibrium defines the Commission's proposal strategy $b^{*}(\omega)$, and the Council's beliefs about $\omega, g^{*}(b)$ and its voting strategy $v_{C}^{*}(b)$. The appropriate solution concept is a perfect Bayesian equilibrium: the Council updates its prior beliefs on $\omega$ when it observes the Commission's proposal. Proposition 2 shows the equilibrium. The proof can be found in Appendix 6.1.

Proposition 2 An equilibrium under rules before Lisbon and under asymmetric information consists of the following strategies and beliefs:

\footnotetext{
${ }^{2}$ Any distribution in the shock will do, but in our calculations we follow other models by having the external shock distributed uniformly over the unit interval, $\omega \sim U[0,1]$.
} 


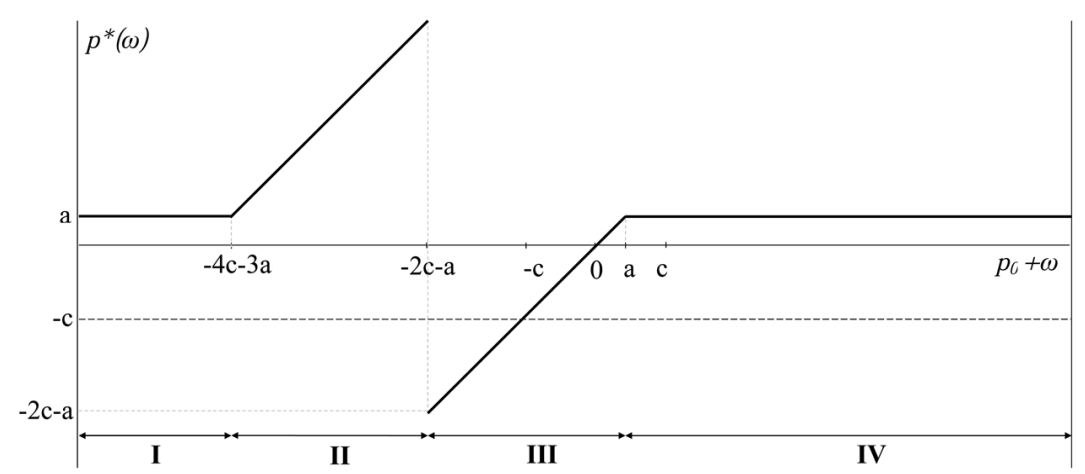

Figure 4: The equilibrium in the policy making process before Lisbon

The equilibrium proposal strategy:

$b^{*}(\omega)= \begin{cases}a-\omega & \text { if } \omega \geq a-p_{0} \text { or } \omega \leq-4 c-3 a-p_{0} \\ 4(a+c)+p_{0} & \text { if }-4 c-3 a-p_{0}<\omega \leq-2 c-a-p_{0} \\ b \in[a, a-1] & \text { if }-2 c-a-p_{0}<\omega \leq a-p_{0}\end{cases}$

The equilibrium beliefs:

$g^{*}(b)= \begin{cases}a-b & \text { if } b \leq p_{0} \text { or } b>4(a+c)+p_{0} \\ \omega \in\left[-4 c-3 a-p_{0},-2 c-a-p_{0}\right] & \text { if } b=4(a+c)+p_{0} \\ \omega \in\left[-2 c-a-p_{0}, a-p_{0}\right] & \text { otherwise }\end{cases}$

The equilibrium voting strategies:

$v_{L}^{*}(b)= \begin{cases}1 & \text { if } b \leq p_{0} \text { or } b \geq 4(a+c)+p_{0} \\ 0 & \text { otherwise }\end{cases}$

And the equilibrium policy is:

$p^{*}(b)=\left\{\begin{array}{cl}b & \text { if } b \leq p_{0} \text { or } b \geq 4(a+c)+p_{0} \\ p_{0} & \text { otherwise }\end{array}\right.$

The solution of this particular game is identical to Gilligan and Krehbiel's (1987) closed rule model. An example of the equilibrium policy result that results from the policy making process is illustrated in Figure 4. This Figure helps to explain the general equilibrium in Proposition 2 in more detail.

When the result of the status quo is to the Commission's right, the Commission is able to perfectly signal this by proposing a policy that is smaller than the status quo, that is $b<p_{0}$. Only in the situation that the status quo result is to the Commission's right, the Commission is willing to make that proposal so this is a perfect signal to the Council that it should accept the proposal. This is what happens in the Figure in interval IV.

For values that are to the Commission's ideal, the Council is uncertain whether a proposal $b>p_{0}$ is more beneficial than the status quo because the 
Council is unaware whether the status quo result is in interval I, II or III. Indeed, under asymmetric information the Commission could have an incentive to propose a policy that results in its ideal policy even though the Council prefers the status quo. The values for which the Council prefers the status quo over the Commissions ideal are located in interval III. Both players are aware of this problem. To solve it, Gilligan and Krehbiel (1987) propose that the Commission makes a policy proposal $b^{\prime}$ that is so large that for all values of $\omega$ that it would want to offer a proposal that is not beneficial for the Council, the Commission would prefer the status quo itself. The offering of such a large proposal thus perfectly signals that the status quo result is not in interval III and therefore the status quo prevails in this interval. In interval I and II the Commission must always make an offer $b \geq b^{\prime}$ to convince the Council that the proposal is more beneficial than the status quo. In interval $\mathbf{I}$, the value of $\omega$ is so small that when the Commission proposes $b=a-\omega$, this is larger than $b^{\prime}$. In interval II, the Commission can no longer propose a policy that results in its ideal. When it would do so, this proposal $b=a-\omega<b^{\prime}$. Therefore the Commission offers the proposal $b^{\prime}$ in interval III.

After Lisbon Under the Lisbon Treaty, the EP has veto right when offered a proposal under closed rule, similar as the Council. In Johns' (2007) words, both actors have the outside option to defer to the status quo.

The sequence of the game is as follows. First Nature reveals $\omega$ to the Commission. This means that the Commission specializes in the policy issue at hand and learns about the relationship between policies and outcomes. In the second stage the informed Commission drafts a policy proposal $b$ and offers it to the Council and to the EP. In the third and final stage the Council and the EP vote on the proposal. If both accept the proposal, the proposal is adopted and otherwise the status quo remains.

The equilibrium defines the Commission's proposal strategy $b^{*}(\omega)$, and the Council's and the EP's beliefs about $\omega, g^{*}(b)$ and their voting strategies $v_{C}^{*}(b)$, $v_{H}^{*}(b) .^{3}$ The appropriate solution concept is a perfect Bayesian equilibrium: the Council and the EP update their prior beliefs on $\omega$ when it observes the Commission's proposal. Proposition 3 shows the equilibrium. Its proof can be found in Appendix 6.2.

Proposition 3 An equilibrium under rules after Lisbon and under asymmetric information consists of the following strategies and beliefs:

\section{The equilibrium proposal strategy:}

\footnotetext{
${ }^{3}$ The Council and the EP hold the same beliefs on $\omega$ because they have the same prior belief that $\omega$ is uniformly distributed and they observe the same Commission proposal. Therefore one belief function $g^{*}(b)$ captures both players' beliefs.
} 


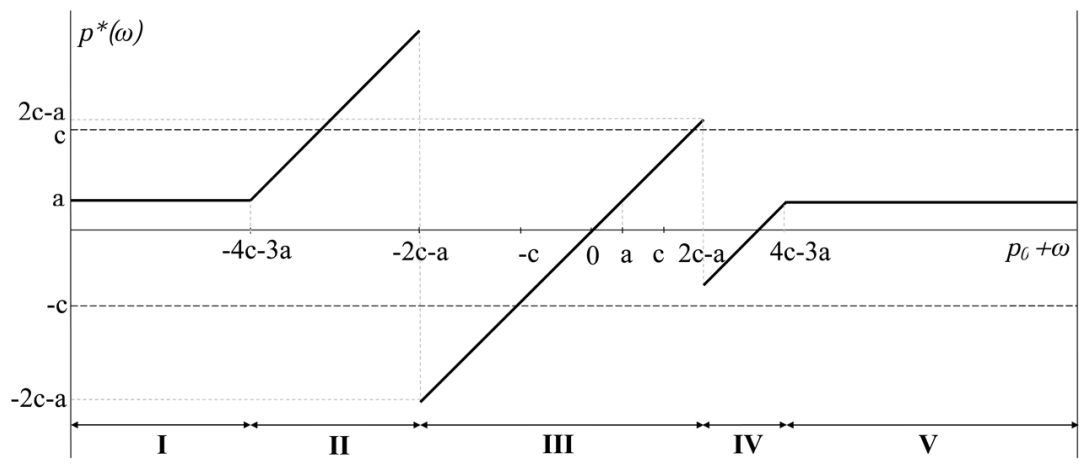

Figure 5: The equilibrium in the policy making process under Lisbon

$b^{*}(\omega)= \begin{cases}a-\omega & \text { if } \omega \geq 4 c-3 a-p_{0} \text { or } \omega \leq-4 c-3 a-p_{0} \\ 4(a+c)+p_{0} & \text { if }-4 c-3 a-p_{0}<\omega \leq-2 c-a-p_{0} \\ 4(a-c)+p_{0} & \text { if } 2 c-a-p_{0}<\omega \leq 4 c-3 a-p_{0} \\ b \in[a, a-1] & \text { if }-2 c-a-p_{0}<\omega \leq 2 c-a-p_{0}\end{cases}$

The equilibrium beliefs:

$g^{*}(b)= \begin{cases}a-b & \text { if } b \leq 4(a-c)+p_{0} \\ \omega \in\left[-4 c-3 a-p_{0},-2 c-a-p_{0}\right] & \text { or } b \geq 4(a+c)+p_{0} \\ \omega \in\left[2 c-a-p_{0}, 4 c-3 a-p_{0}\right] & \text { if } b=4(a+c)+p_{0} \\ \omega \in\left[-2 c-a-p_{0}, 2 c-a-p_{0}\right] & \text { otherwise }\end{cases}$

The equilibrium voting strategies:

$v_{C}^{*}(b)= \begin{cases}1 & \text { if } b \leq p_{0} \text { or } b \geq 4(a+c)+p_{0} \\ 0 & \text { otherwise }\end{cases}$

$v_{H}^{*}(b)= \begin{cases}1 & \text { if } b \geq p_{0} \text { or } b \leq 4(a-c)+p_{0} \\ 0 & \text { otherwise }\end{cases}$

And the equilibrium policy is:

$p^{*}(b)=\left\{\begin{array}{cl}b & \text { if } b \leq 4(a-c)+p_{0} \text { or } b \geq 4(a+c)+p_{0} \\ p_{0} & \text { otherwise }\end{array}\right.$

The interpretation of the equilibrium is similar to Gilligan and Krehbiel's (1987) framework, but now with two legislators instead of one. An example of the equilibrium policy result that results from the policy making process is illustrated in Figure 5. This Figure helps to explain the equilibrium presented in Proposition 3.

The interpretation of interval I and II are similar as in the previous Figure 4: the Commission needs to make a proposal that is certain to be beneficial for the Council and therefore it makes a policy proposal that is so large that for all values of $\omega$ the Council prefers the status quo over the Commission's ideal, the Commission itself prefers the status quo. For very small values of $\omega$ such as in interval I, the Commission then successfully proposes his ideal. 
The same, but reversed, is true for the equilibrium in intervals IV and V. The EP needs to be convinced that a proposal is beneficial as well. Therefore the Commission makes such a small policy proposal that for all the values of $\omega$ the EP prefers the status quo over the Commission's ideal, the Commission itself prefers the status quo. For very large values of $\omega$ such as in interval V, the Commission then successfully proposes his ideal.

In interval III the Commission is unable to make these credible proposals that attract the support of both the Council and the EP, so for moderate values of $\omega$ the status quo prevails.

\subsection{The Commission's Appointment}

What the Council, the EP, and the Commission ultimately care about is the result of the equilibrium policy, that is $p^{*}+\omega$. In Propositions 2 and 3 one can see that the equilibrium policy result is a function of the preferences of the Commission $a$. This means that during the appointment stage, legislators can manipulate the expected result of the policy making process by appointing a different Commission. The policy making processes under the two different institutional rules result in two different equilibria. As a direct consequence, these different equilibria yield different expected utility functions that are dependent on the Commission's preferences $a$.

Both the Council's and the EP's expected utility functions undergo changes because of alterations to the treaty and this has an effect on the type of Commission both players want to appoint. In other words, both the Council and the EP prefer to appoint a different Commission under Lisbon than they preferred to appoint before. In the remainder of this paper these changes are quantified to predict how the negotiations between the Council and the EP are affected. The findings are summarized in Proposition 4.

Proposition 4 Under the assumption of asymmetric information, both the Council and EP prefer a Commission that has preferences closer to the EP's ideal policy under the Lisbon Treaty than before. When both enter the appointment stage they are in agreements about a change in the EP's direction. Therefore Commissions appointed under the Lisbon Treaty are more likely to represent the EP's preferences than Commissions appointed before.

The expected utility functions are central to explain these findings. First there are the expected utilities before the Lisbon Treaty. They are calculated in Appendix 6 and this results in the following equations:

$$
\begin{aligned}
& E U_{C, \text { before }}(a)=-\frac{16}{3} a^{3}-16 a^{2} c-a^{2}-16 a c^{2}-2 a c-\frac{16}{3} c^{3}-c^{2} \\
& E U_{H, \text { before }}(a)=-\frac{16}{3} a^{3}-16 a^{2} c-a^{2}-16 a c^{2}+2 a c-\frac{16}{3} c^{3}-c^{2}
\end{aligned}
$$


Figure 6 displays the utility functions before the introduction of the Lisbon Treaty. The Council's utility function is indicated by a thin line and the EP's utility function by a thick line. ${ }^{4}$ The horizontal axis shows the locational preference of the Commission, $a$, whereas the vertical axis reflects the expected utility.

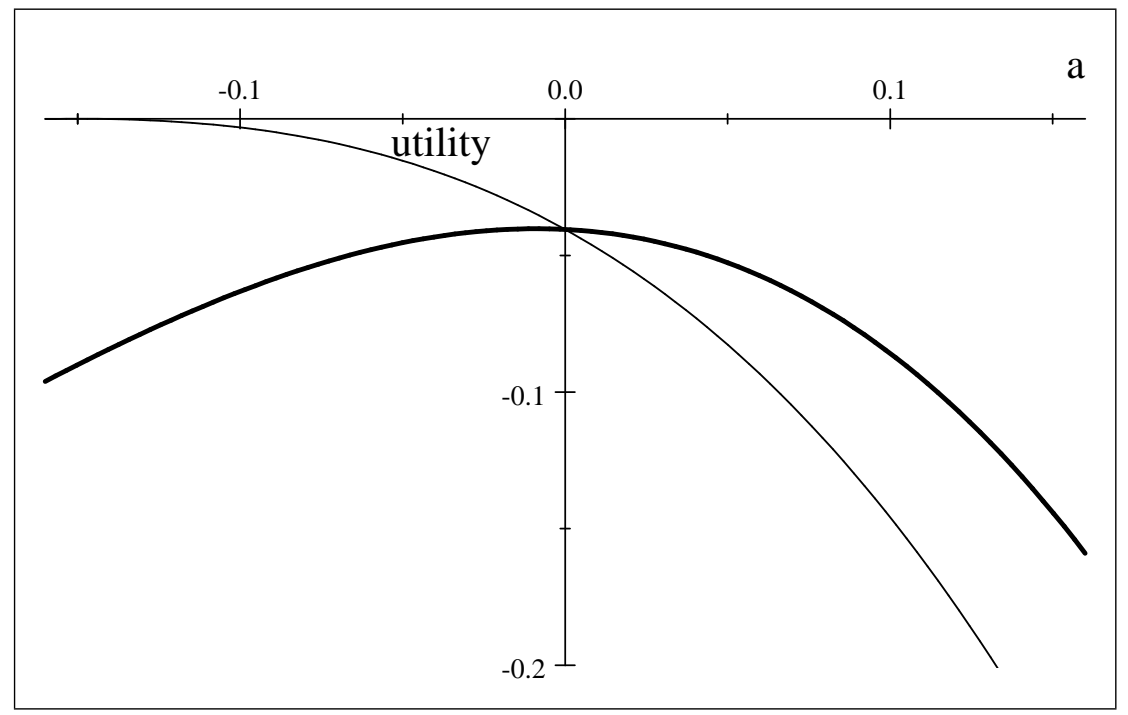

Figure 6: The utility functions of the Council and the Parliament before Lisbon

Figure 6 shows that the Council's utility is maximized when the appointed Commission has the same preferences as the Council, that is when $a=-c$. This is the same result as in the perfect information model and this should hardly amaze. For the Council, there is no conflict between the two roles the Commission fulfills: as the only veto player, the Council prefers to be perfectly informed and to be offered his own ideal policy by the Commission.

The preferences of the EP are somewhat more complex. For the EP, the Commission fulfills two conflicting roles. On the one hand the Commission proposes a policy and the EP likes this policy to be closer to his ideal. This creates an incentive to appoint a Commission that is closer to itself. On the other hand, the Commission's proposals provide information about the consequences of that policy to the veto player that is the Council. If the Council makes an uninformed decision, it often opts for the status quo even though all players prefer a proposal that defeats the status quo if they were perfectly informed. This creates an incentive to appoint a Commission that is closer to the Council's ideal. For

${ }^{4}$ The utility functions are drawn for $c=0.15$. 
the EP, the optimal Commission is therefore more towards the Council's ideal than pure distributional models of perfect information may predict.

Ultimately, the appointed Commission is located somewhere between the two maxima of the expected utility functions. Indeed, there always exists a Commission inbetween these two maxima that both the Council and the EP strictly prefer over any Commission outside of these maxima. The first derivative shows that the maximum utility for the Council is reached at $a_{C \text {,before }}=-c$, whereas the maximum utility for the Parliament is reached at the more complex formulation $a_{H, \text { before }}=\frac{1}{16} \sqrt{64 c+1}-c-\frac{1}{16}$. These two values form the bargaining space over which the Council and the EP negotiate before the introduction of the Lisbon Treaty.

After the introduction of the Lisbon Treaty, the expected utility functions have a different shape because the policy making process changes. These functions are calculated in Appendix 7 and this results in the following equations:

$$
\begin{aligned}
& E U_{C, \text { after }}(a)=-32 a^{2} c-a^{2}-2 a c-\frac{32}{3} c^{3}-c^{2} \\
& E U_{H, a f t e r}(a)=-32 a^{2} c-a^{2}+2 a c-\frac{32}{3} c^{3}-c^{2}
\end{aligned}
$$

Figure 7 shows the two expected utility functions under the Lisbon Treaty. As before, the vertical axis reflects the expected utility, whereas the horizontal axis shows the location of the Commission. The Council's utility function is indicated by a thin line and the EP's utility function is indicated by a thick line. ${ }^{5}$

Comparing the relative maxima with those in the previous Figure shows that the maximum utility for both the Council and the EP is reached for values of $a$ that are larger, that is when the Commission reflects the EP's preferences more. Algebraically, the maximum utility for the Council is now reached at $a_{C, \text { after }}=-\frac{c}{32 c+1}$, which is larger than $a_{C, \text { before }}$. For the EP, maximum utility is now reached at $a_{H, \text { after }}=\frac{c}{32 c+1}$, which is also larger than $a_{H, \text { before }}$. This means that the interval over which the Commission and the EP negotiate is more to the EP's ideal than before Lisbon.

The reason for the shift in utility functions is due to a change in attitude of the appointing bodies towards the two functions the Commission fulfills. Under the Lisbon Treaty, the EP must also approve of proposals to get them adopted. Therefore both the Council and the EP require the EP to be more informed in order to defeat the status quo for more values of $\omega$. Both appointing bodies thus prefer the other to be well informed over having a Commission that perfectly corresponds to their own preferences. One can see this symmetric attitude to the Commission's two functions by noting the symmetry in preferences for the Council and the EP: $a_{C, \text { after }}=-a_{H, a f t e r}$.

\footnotetext{
${ }^{5}$ The utility functions are drawn for $c=0.15$.
} 


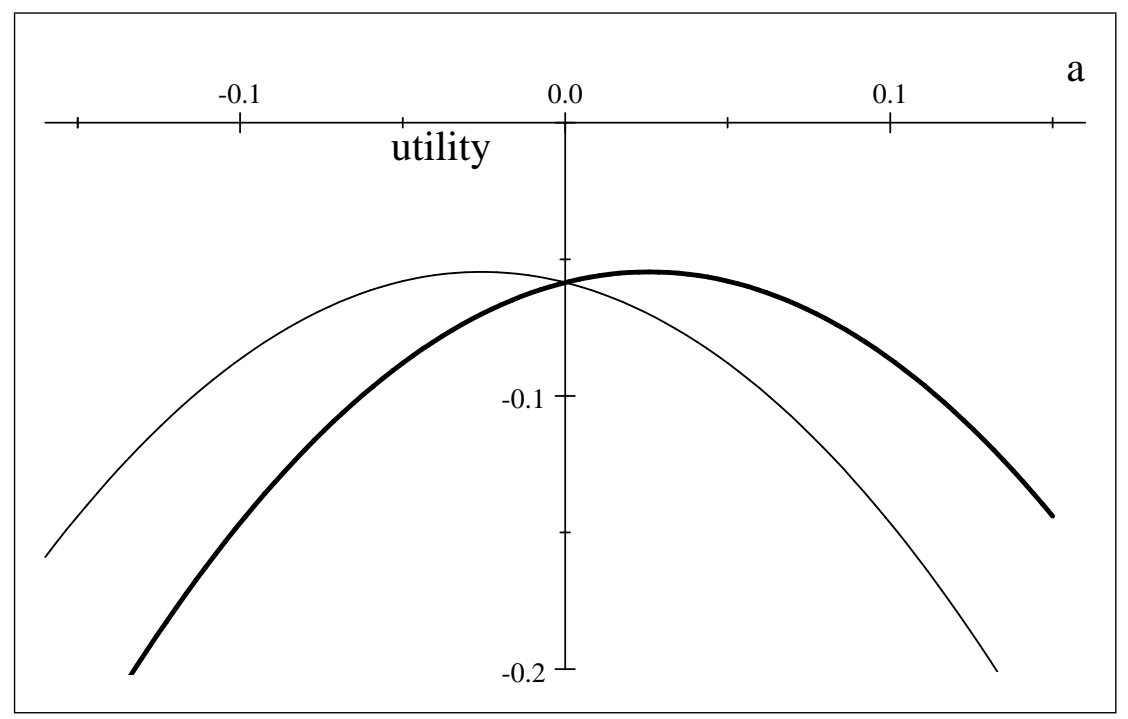

Figure 7: The utility functions of the Council and the Parliament after Lisbon

Let $a_{b e f o r e}^{*}$ and $a_{a f t e r}^{*}$ denote the appointed Commission's equilibrium preferences before and after Lisbon, respectively, with $a_{b e f o r e}^{*} \in\left[a_{C, b e f o r e}, a_{H, \text { before }}\right]$ and $a_{\text {after }}^{*} \in\left[a_{C, a f t e r}, a_{H, a f t e r}\right]$. Because both the upper and lower bound of $a_{a f t e r}^{*}$ are larger than the relative bounds of $a_{b e f o r e}^{*}$, one knows that the Council and the EP negotiate over a set that is closer to the EP's preferences under Lisbon. Figure 8 shows these intervals as a function of how divergent the legislators preferences are, measured by $c$. The dashed curves denote the situation before the Lisbon Treaty, whereas the solid lines refer to the situation after the introduction of the Lisbon Treaty. The thick lines refer to the ideal preferences of the EP, $a_{H, \text { before }}$ and $a_{H, a f t e r}$, whereas the thin ones represent the preferences of the Council, $a_{C \text {,before }}$ and $a_{C, a f t e r}$. Not shown in the Figure are the $45^{\circ}$ and $-45^{\circ}$ line, representing the ideal policy of the EP and the Council respectively.

Figure 8 clearly shows the changing ideal preferences. Before Lisbon both the EP and the Council preferred a Commission close to the Council. The Figure shows that as the divergence in preferences between the EP and the Council increases, both the Council and the EP prefer a Commission that becomes increasingly extreme in the Council's direction: the broken lines follow the $-45^{\circ}$ line. Under the Lisbon Treaty both the EP and the Council prefer a much more moderate Commission that is almost insensitive to how divergent the preferences between the EP and the Council are: the solid lines follow the horizontal axis. The intuition is that legislators that take decisions needs to be informed. Before Lisbon, the EP had little influence in the policy making process, but it did want to have a rather informed Council in order to pass legislation. A Commission that has preferences closer to the EP can convey more information to it, yet 


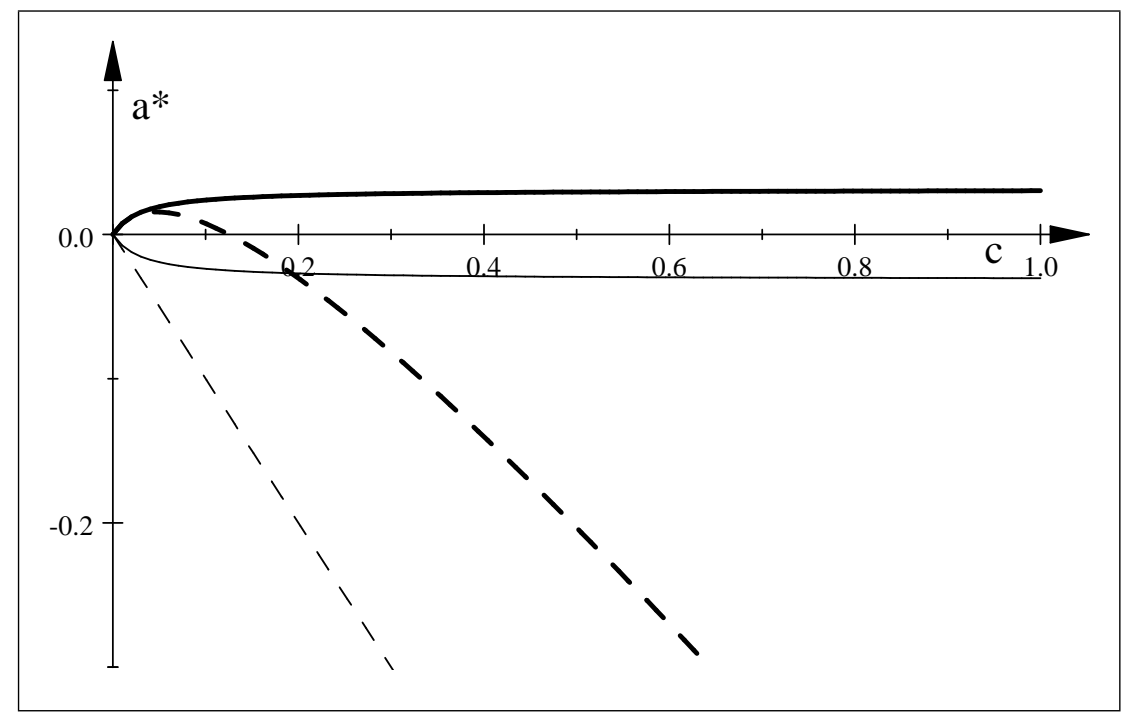

Figure 8: The ideal Commission in function of $\mathrm{c}$

the EP was unable to act on it. Therefore it preferred to have a more informed Council. After Lisbon, the EP has formal policy making power and it requires better information. The fact that the EP now has better information is not only beneficial for the EP itself but also for the Council: if the EP was uninformed it would vote against proposal more often.

Figure 8 shows that ideal preferences of the legislators are impacted by the Lisbon Treaty. Yet strictly speaking, this doesn't prove that the actually appointed Commission is closer to the EP for all values of $c$. One can indeed see that if $c$ is larger than approximately 0.2 , the Commission that is chosen in the appointment equilibrium must be more moderate after Lisbon than before, as the two bargaining sets are disjoint and have no element in common. Yet one cannot deduce from this figure that this holds for $c<0.2$. This could depend on the appointment process that is used and how the utility functions change because of the new Treaty.

As argued by Crombez and Hix (2011), the Lisbon Treaty has no impact on the appointment procedure. Napel and Widgrén (2008) argue that the EP is completely powerless during the appointment of the Commission: in their equilibrium, the EP always accepts the Commission proposed by the Council. They make this claim because the EP cannot make a counteroffer when the Council proposes a Commission. If this is a true representation of the appointment procedure, it is clear that the Commission appointed after Lisbon reflects the EP's position more than before. Indeed, whereas before Lisbon the Council would propose a Commission with the same preferences as itself, indicated in Figure 
9 by the broken line, it would appoint a Commission that is more informative to the EP after Lisbon, as indicated by the solid line. Napel and Widgrén find that the Council duplicates itself when appointing a Commission, a result they verify empirically using data originating from before the introduction of the Lisbon Treaty. My asymmetric information model confirms their results. However, after the Lisbon Treaty, I predict that the balance could shift favorably in the EP's direction.

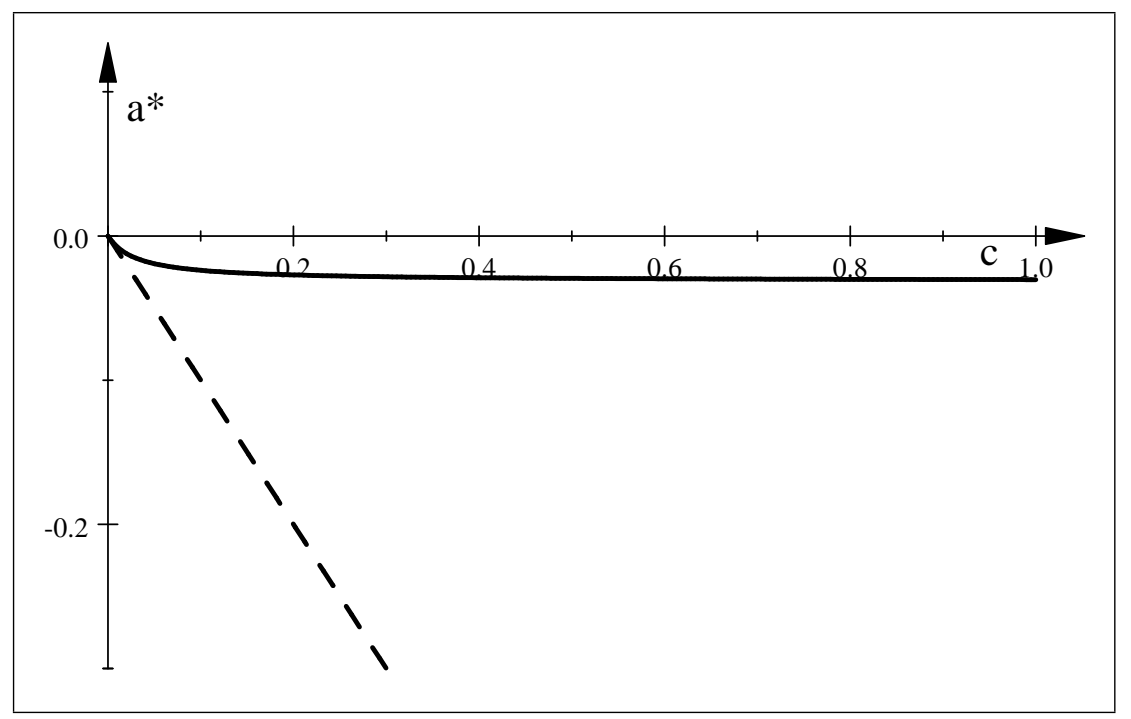

Figure 9: Equilibrium Commission when the EP is powerless in the appointment stage

These findings are also supported when the EP has a more active role during the appointment stage. Suppose indeed that the EP can propose a different Commission to the Council, or that the EP's veto sparks a new round of appointment negotiations as proposed by Hug (1997). In that scenario the ultimatum type bargaining is not appropriate. A system of alternate offerings ask for Rubinstein (1982) type models: players take turns in making an offer and as soon as one accepts an offer the game ends. In alternate offer type negotiations, the equilibrium outcome is dependent on two factors that are influenced by the Lisbon Treaty: the bargaining space over which negotiators hold preferences, and how rapidly utility falls decreases by compromising, that is, the negotiators' willingness to make a compromise.

The move of the bargaining space to the right, in the direction of the EP, suggests that the negotiated outcome will reflect the EP's preferences more. But what with the willingness to make a compromise? To evaluate this, one must look at the marginal utility function of the negotiators. This measures how much 
utility is lost by proposing or accepting a somewhat less favorable Commission. Before Lisbon the first order derivative of the Council's utility function was $-16 a^{2}-32 a c-2 a-16 c^{2}-2 c$, whereas after Lisbon it becomes $-2 a-2 c-64 a c$. The former is more negative than the latter and this shows that the Council's expected utility decreases less by making a less favorable compromise under Lisbon than before. This means that after Lisbon, the Council is prepared to make more concessions. Using the same technique one can also find that after Lisbon the EP is less willing to make concessions than before Lisbon. Therefore I conclude that even in an alternate offering type of game, the new Commission is closer to the EP than before Lisbon.

\section{Conclusions}

This paper looks into the impact of the Lisbon Treaty on the Commission that ultimately is appointed by the Council and the EP. I find that, even though the formal appointment procedure changes little under the new treaty, future Commissions are likely to better reflect the EP's preferences in those areas where the codecision is introduced.

The intuition behind this result is that legislators need information to make decisions. Legislators obtain information about the consequences of policy from the Commission's proposals. The Commission thus fulfills a double role: it is both an agenda setter and an information provider. Before Lisbon only the Council voted on the Commission's proposals and therefore only the Council required information to defeat the status quo. Both the EP and the Council thus preferred a more informed Council over a less informed one. As a result, Commissions appointed before the introduction of the Lisbon Treaty closely reflect the Council's preferences.

The Lisbon Treaty expands the use of the codecision procedure. Now the EP has to approve proposals too. Therefore it is not only the Council, but also the $\mathrm{EP}$ that requires information on the consequences of policy. Both the EP and the Council prefer a more informed EP and as a result Commission appointed after the Lisbon Treaty are more moderate than before. I find that these findings are robust to the assumption that the EP is powerless during the appointment procedure: the results hold even when the EP can make counteroffers. 


\section{Appendix}

\subsection{Proof of Proposition 2}

Proof. We first look at the range of status quo results for which the agenda setter can obtain its ideal.

1. A first range for which the agenda setter is able to propose his ideal is when $p_{0}+\omega \geq b$. The agenda setter then always makes a proposal that moves to the left of the status quo, $b<p_{0}$, which perfectly signals to the legislator to accept the proposal.

2. A second range of status quo results for which the agenda setter is able to propose its ideal is when the status quo result is very small. Yet because of the asymmetric information with regards to the actualization of $\omega$, the agenda setter can have incentives to cheat the legislator and to propose a policy $b=a-\omega$, while the legislator would prefer the status quo. However, the agenda setter has a means to convince the legislator that $\omega$ is low. The agenda setter can propose a very large $b$, such that for all values of $\omega$ that he would like to fool the legislator, the agenda setter himself would prefer the status quo result. When the legislator observes the large proposal, it knows that indeed $\omega$, and thus $p_{0}+\omega$, is very low as well. The agenda setter would like to cheat the legislator when the latter prefers $p_{0}+\omega$ over the agenda setters ideal, so when

$$
\begin{aligned}
\left|p_{0}+\omega,-c\right| & <|a,-c| \\
-p_{0}-\omega-c & <a+c \\
\omega & >-2 c-a-p_{0}
\end{aligned}
$$

Therefore the proposal $\widetilde{b}$ that signals that the agenda setter is telling the truth about the small $\omega$ is such that

$$
\forall \omega>-2 c-a-p_{0}:|\widetilde{b}+\omega, a|>\left|p_{0}+\omega, a\right|
$$

This ultimately leads to the proposal $b$

$$
\begin{aligned}
|b+\omega, a| & >\left|p_{0}+\omega, a\right| \\
b+\omega-a & >a-p_{0}-\omega \\
b & >2 a-2 \omega-p_{0}
\end{aligned}
$$

and since we know that this must be true $\forall \omega>-2 c-a-p_{0}$, we have that

$$
\begin{aligned}
& b>2 a-2\left(-2 c-a-p_{0}\right)-p_{0} \\
& b>2 a+4 c+2 a+2 p_{0}-p_{0} \\
& b>4(a+c)+p_{0}
\end{aligned}
$$


The range of $\omega$ for which the agenda setter is then able to successfully propose his ideal policy $b=a-\omega$ then becomes

$$
\begin{aligned}
a-\omega & >4(a+c)+p_{0} \\
\omega & \leq-3 a-4 c-p_{0}
\end{aligned}
$$

When it is no longer feasible to propose its ideal, the agenda setter proposes $b=4(a+c)+p_{0}$, which it is willing to do until $\omega>-2 c-a-p_{0}$.

3. For all other values of $\omega$, when $\omega \in\left(-2 c-a-p_{0}, a-p_{0}\right)$, the legislator cannot trust the agenda setter and will thus vote against any proposal. Therefore the status quo prevails.

\subsection{Policy Making After Lisbon}

Proof. We first look at the range of status quo results for which the agenda setter can obtain its ideal. This is if $p_{0}+\omega$ is either very small or very large, in such a way that the agenda setter can propose a $b$ to signal this to either legislator $C$ or legislator $H$.

1. For what values of $p_{0}+\omega$ does the agenda setter want to cheat $C$ ? This happens if $C$ would prefer the status quo result over the agenda setters ideal, so when

$$
\begin{aligned}
\left|p_{0}+\omega,-c\right| & <|a,-c| \\
-p_{0}-\omega-c & <a+c \\
\omega & >-2 c-a-p_{0}
\end{aligned}
$$

Then the agenda setter must make a proposal to signal that indeed $\omega$ is smaller than this. It can do so by making a proposal $b$ that he himself would never propose if $\omega$ was that large. This is only if he makes a proposal $b$ such that

$$
\forall \omega>-2 c-a-p_{0}:|b+\omega, a|>\left|p_{0}+\omega, a\right|
$$

This means essentially that

$$
\begin{aligned}
|b+\omega, a| & >\left|p_{0}+\omega, a\right| \\
b+\omega-a & >a-p_{0}-\omega \\
b & >2 a-2 \omega-p_{0}
\end{aligned}
$$

and since we know that this must be true $\forall \omega>-2 c-a-p_{0}$, we have that

$$
\begin{aligned}
& b>2 a-2\left(-2 c-a-p_{0}\right)-p_{0} \\
& b>2 a+4 c+2 a+2 p_{0}-p_{0} \\
& b>4(a+c)+p_{0}
\end{aligned}
$$


The agenda setter is able to propose its ideal as long as $b=a L_{R}-\omega$, so if

$$
\begin{aligned}
a-\omega & >4(a+c)+p_{0} \\
\omega & \leq-3 a-4 c-p_{0}
\end{aligned}
$$

For values of $\omega$ that the agenda setter can no longer propose its ideal, it can propose $b=4(a+c)+p_{0}$ to signal it is not cheating legislator $C$, which it will propose until it is no longer feasible to signal a non-cheating proposal, so until $\omega>-2 c-a-p_{0}$.

2. The same can be done for status quo results that are very large, where the agenda setter proposes a $b$ that is low to signal to legislator $H$ that indeed $p_{0}+\omega$ is very high. So once more, for what values of $\omega$ does the agenda want to cheat on legislator $H$ ? This is when that legislator would prefer the status quo result over the ideal policy result for the agenda setter

$$
\begin{aligned}
\left|p_{0}+\omega, c\right| & <|c, a| \\
p_{0}+\omega-c & <c-a \\
\omega & <2 c-a-p_{0}
\end{aligned}
$$

Then the agenda setter must make a proposal to signal that indeed $\omega$ is larger than this. It can do so by making a proposal $b$ that he himself would never propose if $\omega$ was that small. This is only if he makes a proposal $b$ such that

$$
\forall \omega<2 c-a-p_{0}:|b+\omega, a|>\left|p_{0}+\omega, a\right|
$$

This means essentially that

$$
\begin{aligned}
a-b-\omega & >p_{0}+\omega-a \\
b & <2 a-2 \omega-p_{0}
\end{aligned}
$$

and combined with the necessity that $\omega<2 c-a-p_{0}$, we find that a proposal that signals that the agenda setter is not fooling $L_{L}$ becomes

$$
\begin{aligned}
b & <2 a-2 \omega-p_{0} \\
b & <2 a-2\left(2 c-a-p_{0}\right)-p_{0} \\
b & <2 a-4 c+2 a+2 p_{0}-p_{0} \\
b & <4(a-c)+p_{0}
\end{aligned}
$$

The agenda setter is able to propose its ideal as long as $b=a-\omega$, so if

$$
\begin{aligned}
a-\omega & <4(a-c)+p_{0} \\
\omega & >a-4 a+4 c-p_{0} \\
\omega & >4 c-3 a-p_{0}
\end{aligned}
$$

For values of $\omega$ that the agenda setter can no longer propose its ideal, it can propose $b=4(a-c)+p_{0}$ to signal it is not cheating legislator $H$, which it will propose until it is no longer feasible to signal a non-cheating proposal, so until $\omega<2 c-a-p_{0}$. 
3. For all other values of $\omega$, when $\omega \in\left(-2 c-a-p_{0}, 2 c-a-p_{0}\right)$, the legislator cannot trust the agenda setter and will thus vote against any proposal. Therefore the status quo prevails.

\subsection{Utility Functions Before Lisbon}

$$
\begin{aligned}
E U_{H, \text { before }}(a)= & -\int_{0}^{-4 c-3 a-p_{0}}(c-a)^{2} d \omega \\
& -\int_{-4 c-3 a-p_{0}}^{-2 c-a-p_{0}}\left(4(a+c)+p_{0}+\omega-c\right)^{2} d \omega \\
& -\int_{-2 c-a-p_{0}}^{a-p_{0}}\left(c-p_{0}-\omega\right)^{2} d \omega-\int_{a-p_{0}}^{1}(c-a)^{2} d \omega \\
E U_{H, \text { before }}(a)= & -\frac{16}{3} a^{3}-16 a^{2} c-a^{2}-16 a c^{2}+2 a c-\frac{16}{3} c^{3}-c^{2} \\
E U_{C, \text { before }}(a)= & -\int_{0}^{-4 c-3 a-p_{0}}(a+c)^{2} d \omega \\
& -\int_{-4 c-3 a-p_{0}}^{-2 c-a-p_{0}}\left(4(a+c)+p_{0}+\omega+c\right)^{2} d \omega \\
& -\int_{-2 c-a-p_{0}}^{a-p_{0}}\left(-p_{0}-\omega-c\right)^{2} d \omega-\int_{a-p_{0}}^{1}(a+c)^{2} d \omega \\
E U_{C, \text { before }}(a)= & -\frac{16}{3} a^{3}-16 a^{2} c-a^{2}-16 a c^{2}-2 a c-\frac{16}{3} c^{3}-c^{2}
\end{aligned}
$$

\subsection{Utility Functions After Lisbon}

$$
\begin{aligned}
E U_{H, a f t e r}(a)=- & \int_{0}^{-4 c-3 a-p_{0}}(c-a)^{2} d \omega \\
& -\int_{-4 c-3 a-p_{0}}^{-2 c-a-p_{0}}\left(4(a+c)+p_{0}+\omega-c\right)^{2} d \omega \\
& -\int_{-2 c-a-p_{0}}^{2 c-a-p_{0}}\left(c-p_{0}-\omega\right)^{2} d \omega \\
& -\int_{2 c-a-p_{0}}^{4 c-3 a-p_{0}}\left(-4(a-c)-p_{0}-\omega+c\right)^{2} d \omega \\
& -\int_{4 c-3 a-p_{0}}^{1}(c-a)^{2} d \omega \\
& 32 a^{2} c-a^{2}+2 a c-\frac{32}{3} c^{3}-c^{2}
\end{aligned}
$$




$$
\begin{aligned}
E U_{C, \text { after }}(a)=- & \int_{0}^{-4 c-3 a-p_{0}}(a+c)^{2} d \omega \\
& -\int_{-4 c-3 a-p_{0}}^{-2 c-a-p_{0}}\left(4(a+c)+p_{0}+\omega+c\right)^{2} d \omega \\
& -\int_{-2 c-a-p_{0}}^{2 c-a-p_{0}}\left(p_{0}+\omega+c\right)^{2} d \omega \\
& -\int_{2 c-a-p_{0}}^{4 c-3 a-p_{0}}\left(4(a-c)+p_{0}+\omega+c\right)^{2} d \omega \\
- & \int_{4 c-3 a-p_{0}}^{1}(a+c)^{2} d \omega \\
& 32 a^{2} c-a^{2}-2 a c-\frac{32}{3} c^{3}-c^{2}
\end{aligned}
$$

